\title{
Comparative analysis of mesenchymal stromal cells from different tissue sources in respect to articular cartilage tissue engineering
}

\author{
Luboš Danišovič ${ }^{1}$, Martin Boháč ${ }^{2}$, Radoslav Zamborský ${ }^{3,4}$, Lenka Oravcová ${ }^{5}$ \\ Zuzana Provazníková ${ }^{4}$ Mária Csöbönyeiová ${ }^{5}$ and Ivan Varga ${ }^{5}$ \\ ${ }^{1}$ Institute of Medical Biology, Genetics and Clinical Genetics, Faculty of Medicine, Comenius University in Bratislava, Bratislava, \\ Slovak Republic \\ ${ }^{2}$ Department of Plastic, Reconstructive and Aesthetic Surgery, Faculty of Medicine, Comenius University in Bratislava, \\ Bratislava, Slovak Republic \\ ${ }^{3}$ Department of Orthopaedics, Faculty of Medicine, Comenius University in Bratislava and Children's Faculty Hospital, \\ Bratislava, Slovak Republic \\ ${ }^{4}$ Institute of Anatomy, Faculty of Medicine, Comenius University in Bratislava, Bratislava, Slovak Republic \\ ${ }^{5}$ Institute of Histology and Embryology, Faculty of Medicine, Comenius University in Bratislava, Bratislava, Slovak Republic \\ ${ }^{6}$ Department of Gynaecology and Obstetrics, Faculty of Medicine, Slovak Medical University and University Hospital, \\ Bratislava, Slovak Republic
}

\begin{abstract}
The main goal of this study was a comparison of biological properties of mesenchymal stromal cells (MSCs) obtained from bone marrow, adipose tissue and umbilical cord with respect to articular cartilage regeneration. MSCs were isolated and expanded in vitro up to the third passage. The kinetics of proliferation was analyzed by cell analyzer CEDEX XS and expression of selected markers was assessed by flow cytometry. The morphology was analyzed by inverted microscope and TEM. Pellet culture system and chondrogenic medium containing TGF- $\beta 1$ was used to induce chondrogenic differentiation. Chondrogenesis was analyzed by real-time PCR; the expression of collagen type I and type II was compared. MSCs from all sources showed similar kinetics of proliferation and shared expression of CD73, CD90 and CD105; and were negative for CD14, CD20, CD34 and CD45. Observation under inverted microscope and TEM showed similar morphology of all analyzed MSCs. Cells from all sources underwent chondrogenic differentiation - they expressed collagen type II and acid mucopolysaccharides typical for hyaline cartilage. On the basis of obtained results it should be emphasized that MSCs from bone marrow, adipose tissue and umbilical cord share biological properties. They possess the chondrogenic potential and may be utilized in cartilage tissue engineering.
\end{abstract}

Key words: Mesenchymal stromal cells - Bone marrow - Adipose tissue - Umbilical cord Cartilage tissue engineering

\section{Introduction}

Despite the advances in modern medicine, there are still many conditions due to injuries or pathological processes that affect articular cartilage. They are usually accompa-

Correspondence to: Lubos Danisovic, Institute of Medical Biology, Genetics and Clinical Genetics, Faculty of Medicine, Comenius University in Bratislava, Sasinkova 4, 81108 Bratislava, Slovak Republic

E-mail: lubos.danisovic@fmed.uniba.sk nied by retarded or restricted healing and significant pain. Moreover, they may lead into total immobilization of affected individuals. Unfortunately, many conventional therapies, including conservative and surgical approaches fail and do not produce expected results. Thus, research of stem cells, which have ability to promote and accelerate the healing process, has attracted the attention of many clinicians and researchers in field of regenerative medicine (Mardones et al. 2015; Pastides et al. 2015).

Stem cells possess unique biological characteristics which make them promising tool of regenerative medicine. These 
are mainly capability of long-term self-renewing, multilineage differentiation potential (plasticity) and active ability of migration to diseased tissues (Shanti et al. 2007). They are generally divided into embryonic and adult stem cells. The utilization of embryonic stem cells is restricted by ethical considerations in many countries. Therefore, the research is focused on more acceptable adult stem cells - termed as mesenchymal stromal (stem) cells (MSCs) (Heslop et al. 2015).

MSCs can be easily obtained from different tissue sources, including bone marrow, adipose tissue, umbilical cord, placenta, skin, etc. These adherent cells are characterized according to the expression of several surface antigens. They have to be positive at least for CD73, CD90 and CD105; and negative for CD45, CD34, CD14 or CD11b, CD79a or CD19 and HLA-DR. Moreover, MSCs must differentiate to osteoblasts, adipocytes and chondroblasts in vitro (Dominici et al. 2006). More recently, genomic studies performed on MSCs provided evidence of pluripotent marker's (Oct-4, Nanog and Sox2) expression. These findings clarified their undifferentiated state (Patterson et al. 2012). Moreover, Kestendjieva et al. (2008) showed that MSCs expressed survivin, which is also widely expressed in most human cancers (Halasova et al. 2009, 2013).

The main goal of this study was to perform comprehensive characterization and comparison of selected biological properties of MSCs isolated from bone marrow, adipose tissue and umbilical cord in respect to their potential clinical utilization in cartilage regeneration.

\section{Materials and Methods}

The sampling protocols and experimental protocols were approved by local Ethical committee of University hospital in Bratislava. All sampling procedures were performed always after obtaining patient's written and verbal informed consent in compliance with the Helsinki Declaration during planed surgeries or physiological deliveries. All chemical reagents were purchased from Sigma-Aldrich (USA) unless otherwise noted.

\section{Cell isolation and in vitro expansion}

Bone marrow-derived MSCs (BMSCs) were isolated from fresh samples $(n=3)$, and supplemented with $20 \mathrm{U} / \mathrm{ml}$ heparin in a sterile physiological solution. To obtain nucleated cells, gradient centrifugation using Ficoll ${ }^{\circledR}$ PM400 at $1800 \mathrm{rpm}$ for $30 \mathrm{~min}$ was performed. The obtained cells were carefully washed in phosphate-buffered saline (PBS) then centrifuged at $1200 \mathrm{rpm}$ for $6 \mathrm{~min}$. Pellets were resuspended in a complete culture medium consisting of $\alpha$-MEM, 10\% fetal bovine serum (FBS, PAA, Austria), $100 \mathrm{U} / \mathrm{ml}$ Penicillin and $100 \mu \mathrm{g} / \mathrm{ml}$ Streptomycin. The cells (200 000 cells $/ \mathrm{ml}$ ) were plated in $100 \mathrm{~mm}$ Petri dishes and were cultured at $37^{\circ} \mathrm{C}$ in a humidified atmosphere containing $5 \% \mathrm{CO}_{2}$. After $24 \mathrm{~h}$, non-adherent cells were removed by aspiration the culture medium. During subsequent cultivation, the medium was refreshed every three days. After 8-12 days, cells were detached by $0.25 \%$ trypsin (Gibco, USA) and sub-cultured up to the third passage.

Adipose tissue-derived MSCs (ATSCs) were obtained from fresh lipoaspirates $(n=6)$ by standard protocol. Briefly, lipoaspirates were roughly rinsed with sterile PBS to remove contaminating erythrocytes. This procedure was repeated several times until the colour of PBS became light pink. After that, adipose tissue fragments were digested with $0.1 \%$ collagenase type I (PAA, Austria) at $37^{\circ} \mathrm{C}$ for $45 \mathrm{~min}$ with constant shaking, followed by centrifugation at $1200 \mathrm{rpm}$ for $10 \mathrm{~min}$. Supernatant containing fat and floating mature adipocytes was aspired and cell pellet was resuspended in D-MEM/F12 containing 10\% FBS and centrifuged at $1200 \mathrm{rpm}$ for $5 \mathrm{~min}$. Final pellet was resuspended in complete culture medium consisted of D-MEM/ F12 supplemented with $10 \%$ FBS, $100 \mathrm{U} / \mathrm{ml}$ Penicillin and $100 \mu \mathrm{g} / \mathrm{ml}$ Streptomycin; and filtered through a $40 \mu \mathrm{m}$ cell strainer (Becton Dickinson, USA). Obtained cells were plated at density of $1 \times 10^{6}$ cells $/ \mathrm{ml}$ into $100 \mathrm{~mm}$ Petri dishes and were cultured at $37^{\circ} \mathrm{C}$ in a humidified atmosphere containing $5 \% \mathrm{CO}_{2}$. After $24 \mathrm{~h}$, non-adherent cells were removed by aspiration medium. During subsequent cultivation, the medium was refreshed every three days. After 7-10 days, cells were detached by $0.25 \%$ trypsin and sub-cultured up to the third passage.

Umbilical cord-derived MSCs (UCSCs) were isolated from fresh samples $(n=6)$ by explant technique. Briefly, cords were rinsed with PBS to remove contaminating blood. The cords were cut into small pieces (approximately $3 \mathrm{~cm}$ ) and blood vessels were removed from each piece after incising the cord lengthwise. Afterwards, cord was cut into small fragments with an approximate diameter of $4 \mathrm{~mm}$ which were transferred into $100 \mathrm{~mm}$ Petri dishes. After $5 \mathrm{~min}$, when fragments adhered to surface of Petri dish, the complete culture medium consisted of D-MEM/ F12 supplemented with $10 \%$ FBS, $100 \mathrm{U} / \mathrm{ml}$ Penicillin and $100 \mu \mathrm{g} / \mathrm{ml}$ Streptomycin was carefully added. During subsequent cultivation, the medium was refreshed every three days. After 10 days, tissue fragments were removed and UCSCs were cultured until confluence. Afterwards they were detached by $0.25 \%$ trypsin and sub-cultured up to the third passage.

\section{Kinetics of proliferation}

The evaluation of the growth characteristics of MSCs was performed by generating a growth curve prepared 
according to a standard method. Briefly, suspension of MSCs $\left(5 \times 10^{4}\right.$ cells $\left./ \mathrm{ml}\right)$ at passage 3 was seeded into $60 \mathrm{~mm}$ Petri dishes (TPP, Switzerland). During the next 7 days of cultivation, three dishes were monitored on a daily basis for density. Growth curves were plotted and population doubling time (PDT) was calculated by means of the formula: PDT = days in exponential phase $/(\log$ $\mathrm{N} 2-\log \mathrm{N} 1) / \log 2$, where N1 was the number of cells at the beginning of the exponential growing phase, and $\mathrm{N} 2$ was the number of cells at the end of the exponential growing phase.

\section{Flow cytometry}

MSCs assigned for flow cytometry were detached by $0.25 \%$ trypsin digestion and then resuspended in blocking buffer consisting of PBS with $0.5 \%$ bovine serum albumin (PAA, Austria). The MSC Phenotyping kit (Miltenyi Biotec) containing antibodies against human CD14, CD20, CD34, CD45, CD73, CD90 and CD105 were used in all experiments. Cell suspensions processed according to protocol provided by manufacturer. The samples were analyzed by MACSQuant ${ }^{\circledR}$ Analyzer (Miltenyi Biotec).

\section{Morphological analysis}

The morphology of MSCs was continually analysed during cultivation using an inverted microscope Zeiss Axiovert 100 (Carl Zeiss, Germany).

MSCs asigned for transmission electron microscopy (TEM) were fixed in $2.5 \%$ glutaraldehyde (SigmaAldrich), $\mathrm{pH} 7.2$, at $4^{\circ} \mathrm{C}$ for four hours. After fixation, cells were carefully rinsed by PBS and post-fixed with $2 \%$ osmium tetraoxide for 2 hours, then rinsed in distilled water and dehydrated in a graduated series of ethanol. Subsequently, the samples were embedded in Durcupan and cut into semi-thin sections. The obtained sections were stained by toluidine blue for 10 minutes, and cut into ultra-thin sections. Then, they were mounted on 200 mesh copper grids, double stained using uranyl acetate and lead citrate and examined using a TEM FEI Morgagni 268D (FEI, USA).

\section{Chondrogenic differentiation}

For chondrogenic differentiation, a three-dimensional pellet culture system was used. Pellets were formed by centrifugation of $5 \times 10^{5} \mathrm{MSCs}$ and control chondrocytes from first passage at $1500 \mathrm{rpm}$ for $10 \mathrm{~min}$ in $15 \mathrm{ml}$ polypropylene tubes (TPP, Switzerland). The chondrogenic medium consisted of DMEM/F12 1:1, 10\% FBS, 100 U/ $\mathrm{ml}$ Penicillin and $100 \mu \mathrm{g} / \mathrm{ml}$ Streptomycin and $5 \mathrm{ng}$ TGF$\beta 1$ (STEMCELL Technologies, USA). All tubes were maintained in the incubator at $37^{\circ} \mathrm{C}$ with humidified atmosphere of $5 \% \mathrm{CO}_{2}$. The culture medium was carefully refreshed every third day during 21 days. After termination of the experiment, histological evaluation of pellets was performed by Hematoxilin and Eosin (HE) as well as Alcian blue staining (AB).

\section{Gene expression analysis}

Total RNA was extracted from MSCs using GeneJET RNA Purification Kit (Thermo Scientific, USA) according to the manufacturer's recommendations. First-strand cDNA was synthesized from total RNA with Maxima First Strand cDNA Synthesis Kit for RT-qPCR (Thermo Scientific). The reaction was performed according to protocol recommended by manufacturer. The thermal cycling conditions were composed of $25^{\circ} \mathrm{C}$ for $10 \mathrm{~min}, 50^{\circ} \mathrm{C}$ for $15 \mathrm{~min}$ and $85^{\circ} \mathrm{C}$ for $5 \mathrm{~min}$. Obtained cDNA was used as a template for quantitative PCR to determine the expression level of the selected genes (for collagen type I and II). Glyceraldehyde3-phosphate dehydrogenase (GAPDH) was used as housekeeping gene. All primers used in this study are listed in Table 1. The PCR reactions were performed on Eco RealTime PCR System (Illumina). The reaction was performed in $5 \mu \mathrm{l}$ mixture consisted of $2.5 \mu \mathrm{l}$ Maxima Probe/ROX qPCR Master Mix (2x) (Thermo Scientific), $0.25 \mu \mathrm{l}$ of each primer - TaqMan ${ }^{\oplus}$ Gene Expression Assay (Applied Biosystems), $0.5 \mu \mathrm{l}$ of cDNA and the rest of the reaction volume was adjusted with water. The thermal cycling conditions were composed of $50^{\circ} \mathrm{C}$ for 2 min followed by an initial denaturation step at $95^{\circ} \mathrm{C}$ for $10 \mathrm{~min}, 45$ cycles at $95^{\circ} \mathrm{C}$ for $15 \mathrm{~s}, 60^{\circ} \mathrm{C}$ for $1 \mathrm{~min}$. Expression of all analyzed genes was normalized to GAPDH.

\section{Statistical analysis}

Data were analyzed using SPSS 14.0 (SPSS Inc., USA) and subjected to one-way analysis of variance with a Tukey post hoc test to determine significant difference $(p<0.05)$ in PDT and gene level expression between BMSCs, ATSCs and UCSCs. Data are presented as the mean \pm standard deviation (SD).

Table 1. Primers used in Quantitative real-time polymerase chain reaction

\begin{tabular}{ll}
\hline Target gene & $\begin{array}{l}\text { Accession Number of TaqMan } \\
\text { Gene Expression Assay }\end{array}$ \\
\hline COL1A1 & Hs00164004_m1 \\
COL2A1 & Hs00156568_m1 \\
GAPDH & Hs03929097_g1 \\
\hline
\end{tabular}



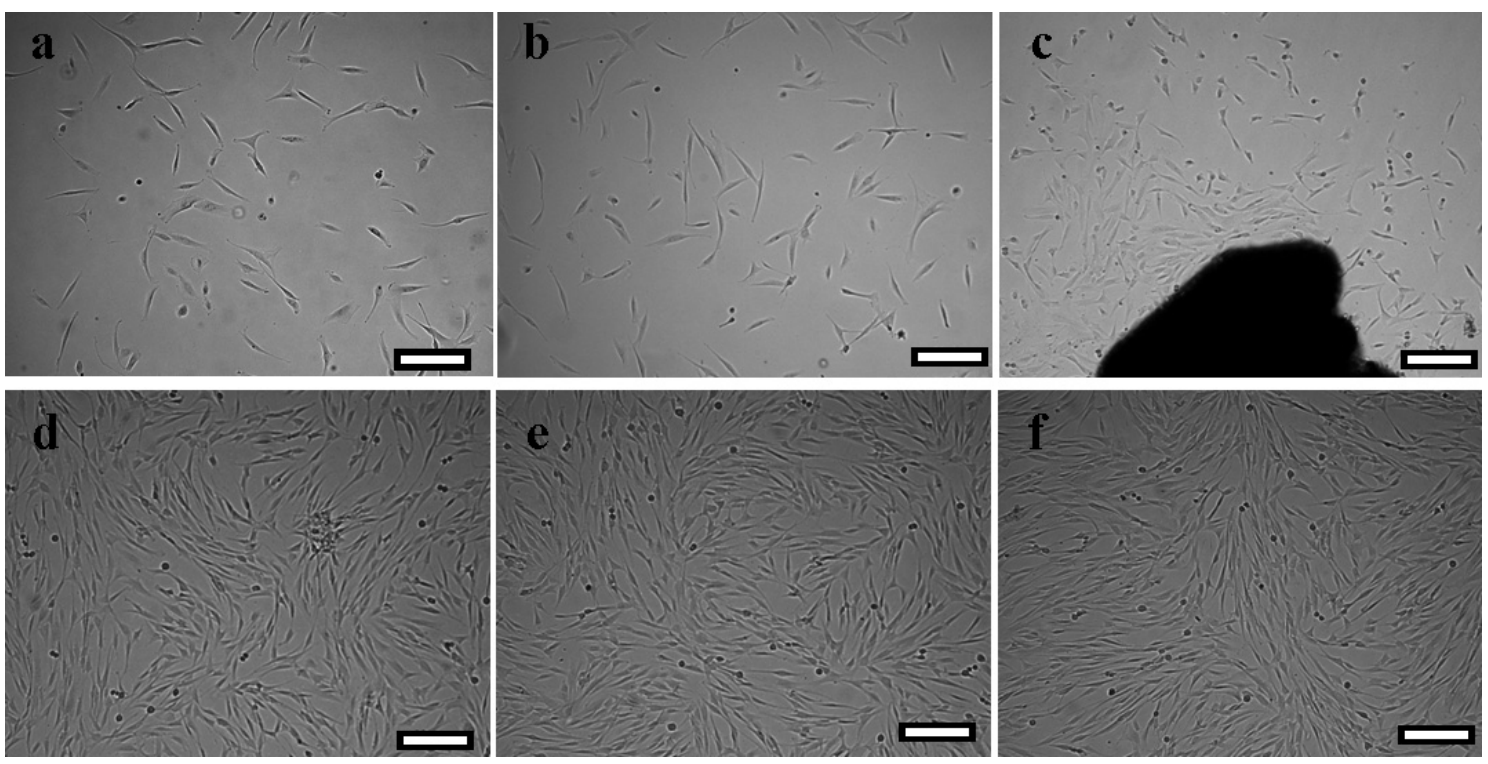

Figure 1. Morphological features of isolated human mesenchymal stromal cells (MSCs): primary isolated BMSCs (a), primary isolated ATSCs (b), UCSCs outgrowth from tissue fragment (c), confluent layer of BMSCs in third passage (d), confluent layer of ATSCs in third passage (e), confluent layer of UCSCs in third passage (f). Scale bar $=20 \mu \mathrm{m}$. BMSCs, bone marrow-derived MSCs; ATSCs, adipose tissue-derived MSCs; UCSCs, umbilical cord-derived MSCs.

\section{Results}

\section{Cell isolation and in vitro expansion}

In case of BMSCs and ATSCs, the cells adhered to substrate and began to proliferate. They display spindle-shaped appearance (Figures 1a,b). After several days they started to form colonies and later on they reached $80 \%$ confluence. In that time they displayed typical fibroblast-like morphology

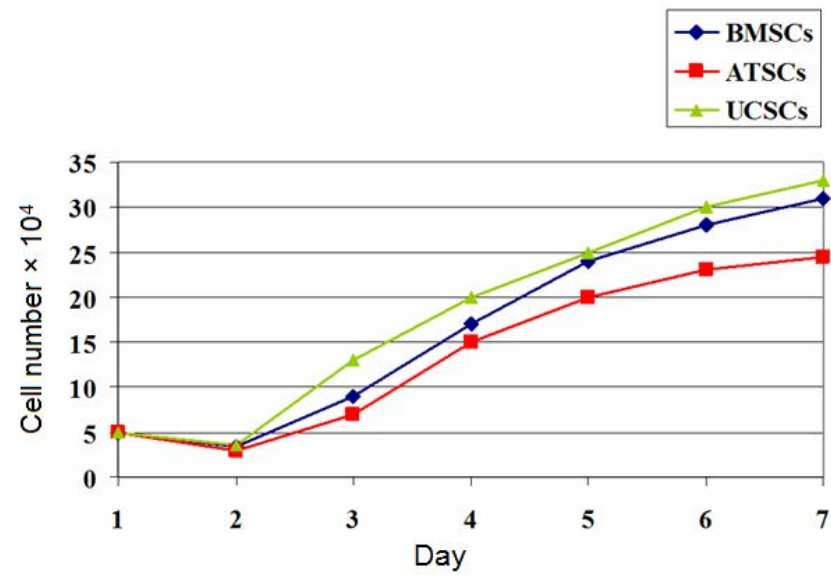

Figure 2. Representative growth curves of mesenchymal stromal cells derived from bone marrow (BMSCs), adipose tissue (ATSCs) and umbilical cord (UCSCs) in third passage. and were sub-cultured until third passage. In case of UCSCs, fragment of tissues quickly adhered to substrate and after several days the migration of cells were recorded (Figure 1c). On the $10^{\text {th }}$ day of culture, the fragments were removed; cells with typical fibroblast morphology reached confluence and were sub-cultured until third passage. All analyzed cells displayed typical prolonged fibroblast-like morphology during further cultivation (Figures 1d,e,f).

\section{Kinetics of proliferation}

All analyzed MSCs from third passage shared similar kinetics of proliferation (Figure 2). They had very short lag phase, which was followed by an exponential growth phase in the duration of 5 days. Population doubling time was significantly higher in case of ATSCs (Figure 3) but they have lower expansion capacity when compared to BMSCs and UCSCs.

\section{Expression of surface antigens}

Flow cytometric analysis revealed that all MSCs were positive for expression of CD73, CD90 and CD105, but negative for CD14, CD20, CD34 and CD4 (Table 2).

\section{Morphology of MSCs}

Light microscopy analysis showed that MSCs from third passage display typical fibroblast-like morphology (Figure 1). 
TEM analysis showed normal ultrastructure of protheosynthetically active cells (Figure 4). They had irregular shape with noticeable nuclei (often eccentrically located) with huge amount of euchromatine. Every nucleus contained 1 to 3 nucleoli. All cells had prominent rough endoplasmic reticulum. ATSCs also contained residual lipid droplets.

\section{Histological evaluation of pellets}

When BMSCs, ATSCs and UCSCs were centrifuged, the condensation of the pellets into single aggregates was observed after 24 hours. The condensed pellets grew continually during further 21 days. They gradually became white and opaque. Photomicrographs of HE stained samples (Figure 5a,b,c) showed a homogenous cell distribution in all samples. Cells were mostly round with darkly stained nuclei what indicate their excessive proliferation. In case of pellets consisted of BMSCs we recorded higher compactness in comparison with ATSCs and UCSCs. However the lacuna formation, typical for hyaline cartilage, was not recorded. On other hand, Alcian blue staining revealed presence of acid mucopolysaccharides in all analyzed samples (Figure 5d,e,f).

\section{Expression of cartilage-specific genes}

The cartilage-specific genes expression analysis revealed increased production of collagen type II typical for articular cartilage in all types of MSCs (Figure 6). However, the expression of collagen type II was lower than in control group; the highest chondrogenic potential was recorded in case of BMSCs. On the other hand the expression of collagen type I, typical for fibrillar cartilage, was significantly lower in all aggregates which provide evidence of hyaline cartilage production.

\section{Discussion}

Recently, regenerative medicine and tissue engineering provides novel promising approach which should be used for treatment patients with damaged articular cartilage. It combines different types of cells, including primitive undifferentiated stem cells, different biomaterials and ap-

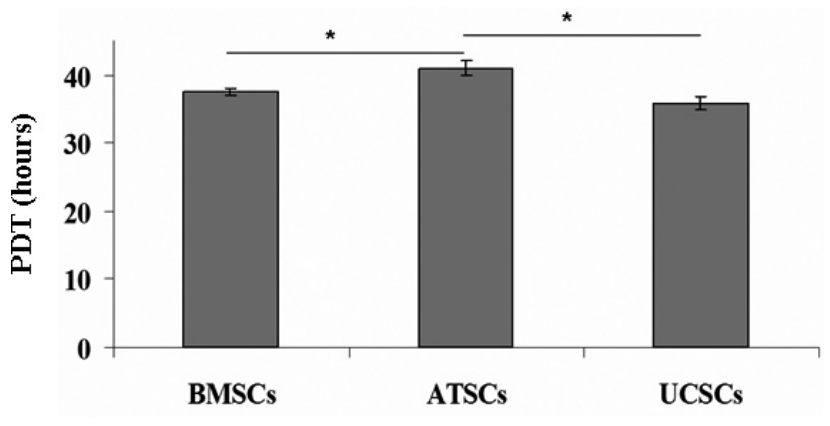

Figure 3. Analysis of PDT in third passage. PDT in case of ATSCs was significantly higher then in BMSCs and UCSCs. Data are means $\pm \mathrm{SD}, n=3,{ }^{*} p<0.01$. PDT, population doubling time. For more abbreviations see Fig. 1 .

propriate growth factors to prepare artificial cartilage tissue with suitable biological, biochemical and biomechanical properties (Makris et al. 2015). Selection of suitable cells and thorough knowledge of their biological properties belongs to most important prerequisite prior to their clinical application. In order to prepare the cartilage, chondrocytes appeared to be most suitable cell type. However, they undergo dedifferentiation process when expanded in vitro. They gradually change their morphology and the expression of collagen type II is replaced by production of collagen type I typical for fibrillar cartilage. These events may be overlapped by adding the specific growth factors (e.g. BMP-2 and TGF- $\beta 1$ ) (Claus et al. 2012; McNary et al. 2014). More recently, the interest of scientists has been focused on utilization of multipotent MSCs, which may

Table 2. Analysis of surface markers expression in BMSCs, ATSCs and UCSCs

\begin{tabular}{cccccccc}
\hline & CD14 & CD20 & CD34 & CD45 & CD73 & CD90 & CD105 \\
\hline BMSCs & - & - & - & - & + & + & + \\
ATSCs & - & - & - & - & + & + & + \\
UCSCs & - & - & - & - & + & + & + \\
\hline
\end{tabular}

All analyzed cells expressed markers of mesenchymal stromal cells and were negative for endothelial and hematopoietic markers (+ more than 95\%; - less than 5\%). BMSCs, bone marrow-derived MSCs; ATSCs, adipose tissue-derived MSCs; UCSCs, umbilical cord-derived MSCs.

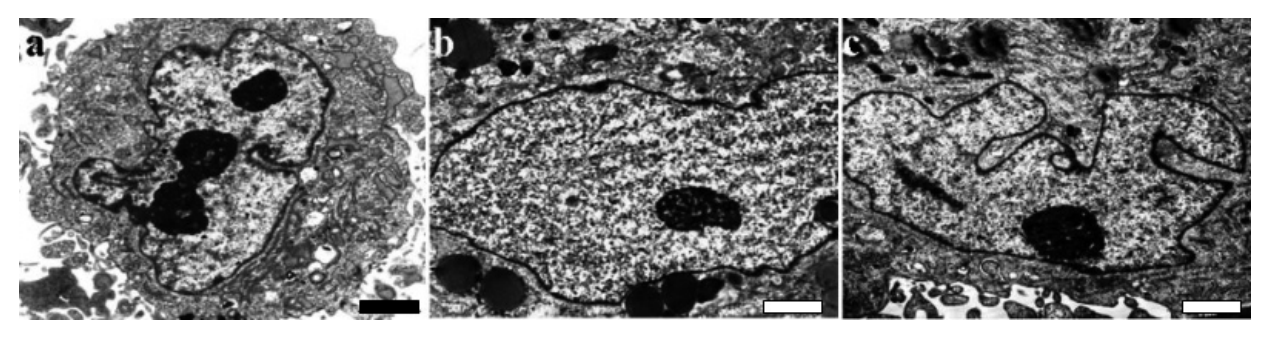

Figure 4. Representative electron micrographs of mesenchymal stromal cells: BMSCs (a), ATSCs (b), UCSCs (c). Scale bar $=2 \mu \mathrm{m}$. For abbreviations see Fig. 1. 


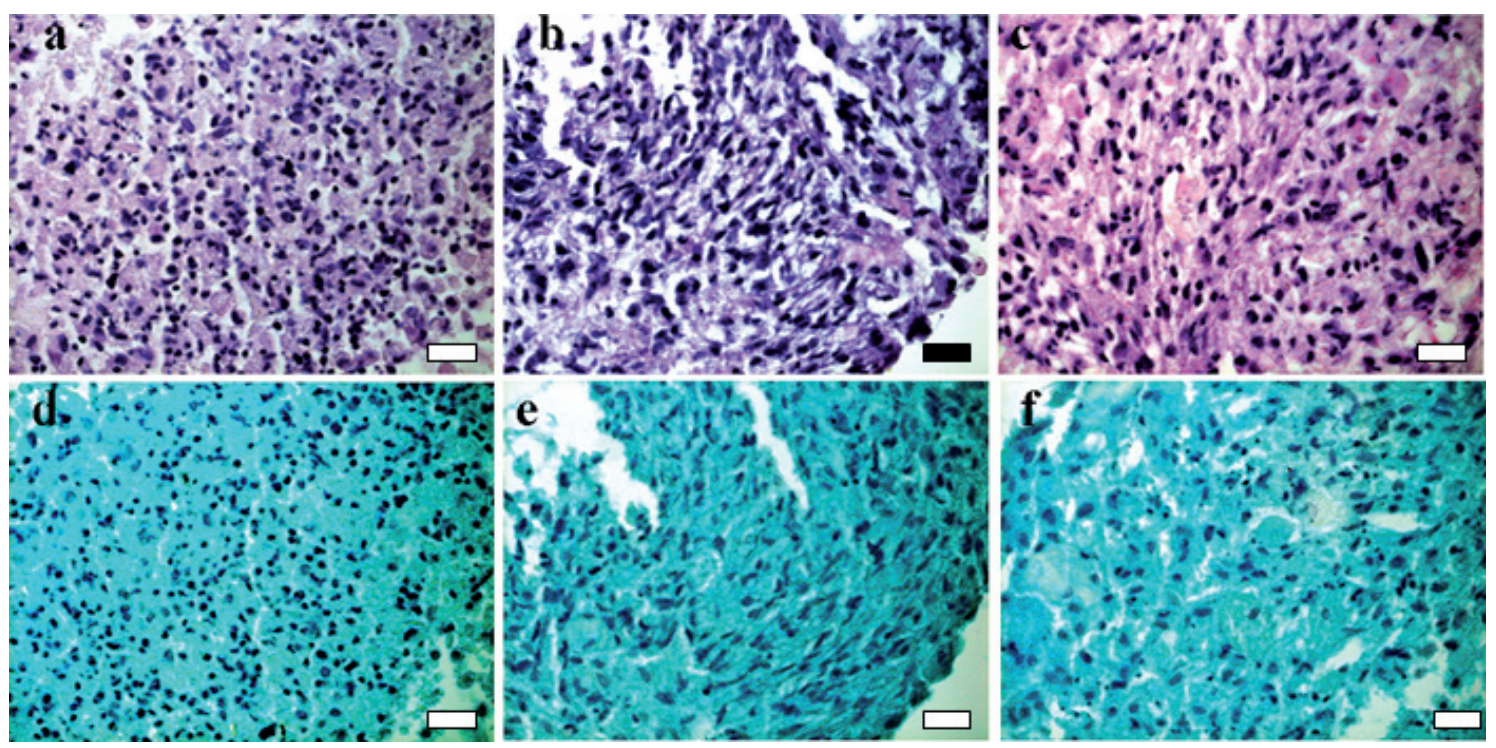

Figure 5. Representative micrographs of mesenchymal stromal cells: BMSCs (a, HE), ATSCs (b, HE), UCSCs (c, HE), BMSCs (d, AB), ATSCs $(\mathbf{e}, \mathrm{AB}$,$) , UCSCs (\mathbf{f}, \mathrm{AB})$ cultured in pellet. All cell produced its own extracellular matrix which contained predominantly acid mucopolysaccharides typical for hyaline cartilage. Scale bar $=20 \mu \mathrm{m} \mathrm{HE}$, Hematoxilin and Eosin staining; AB, Alcian blue staining. For more abbreviations see Fig. 1.

be easily obtained from different tissues, including bone marrow, adipose tissue, umbilical cord etc. It was shown that these MSCs undergo chondrogenic differentiation in vitro. The best results were obtained by using $3 \mathrm{D}$ (micromass) culture technique, which mimic condition in vivo. It provides $3 \mathrm{D}$ architecture of tissue in which the cells are

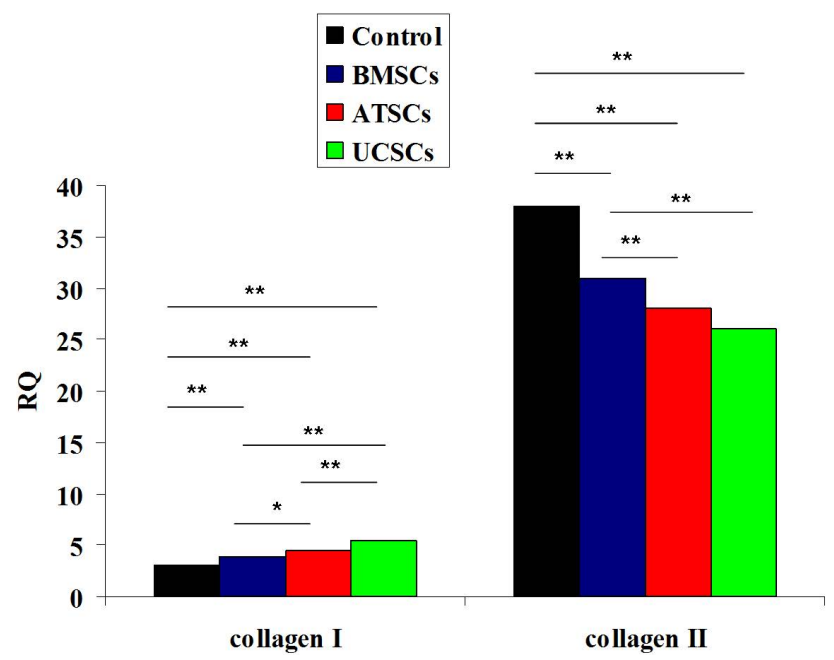

Figure 6. Chondrogenic differentiation of BMSCs, ATSCs and UCSCs gene level expression was significantly different when compared with control - chondrocytes from first passage $(n=3$, $\left.{ }^{* *} p<0.01,{ }^{*} p<0.05\right)$. RQ, relative quantitative expression. For more abbreviations see Fig. 1 . in deep contact and may influence each other by paracrine signaling (Mara et al. 2010). This effect is also additively enhanced by supplementation of growth factors such as TGF- $\beta 1$, TGF- $\beta 3$, BMP-2, BMP-6 and GDF-5 (Murphy et al. 2015; Shademan et al. 2015).

In this study, we performed analysis of selected biological characteristics of MSCs from bone marrow, adipose tissue and umbilical cord in respect to potential application in articular cartilage healing. All experiments were performed on the MSCs in third passage on the basis of generally accepted premise of minimal effect of short-term cultivation on biological properties. The cultures were established according to standard protocols. All studied MSCs displayed similar proliferation kinetics and morphological features as documented by light and electron microscopy. This observation was fully consistent with results of other authors (Hsiao et al. 2012; Vishwanath et al. 2013; Wang et al. 2014). After reaching the confluence they were sub-cultured up to third passage and were characterized according to expression of surface antigens. We found similar phenotype of BMSCs, ATSCs and UCSCs, they shared expression of CD73, CD90 and CD105, but they did not express CD14, CD20, CD34 and CD4 typical for endothelial and hematopoietic cells (Pittenger et al. 1999). On the other hand, this argument, mainly in case of CD34 is not strictly accurate. Some authors provide evidence for CD34 expression in tissue resident MSCs. They attribute negativity for CD34 as a consequence of cell cultivation (Lin et al. 2012; Braun et al. 2013; Zimmerlin et al. 2013). 
Afterwards, we analyzed the chondrogenic differentiation potential of all MSCs. We used generally accepted micromass (pellet) culture system with chondrogenic medium contained TGF- $\beta 1$ to induce chondrogenesis. Our findings fully support the use of BMSCs, ATSCs and UCSCs for purposes of articular cartilage healing. The chondrogenic nature in our micromass cultures was supported mainly by the expression of acid mucopolysaccharides and by the expression of collagen type II mRNA, as confirmed by real time RT-PCR analysis. However, we found that the best chondrogenic potential was in case BMSCs but in case of ATSCs and UCSCs this potential should be enhanced by optimization of culture techniques as it was indicated by other authors (Shih et al. 2011; Alimperti et al. 2014; Shang et al. 2014). More recently, interesting results were obtained by Subramanian et al. (2015), who suggested different biological properties, including chondrogenic differentiation potential of MSCs derived from various compartments of the human umbilical cord. In addition, we did not observe the lacuna formation typical for hyaline cartilage. This finding was in contrast to the results documented by Shademan et al. (2015), who recorded lacunae in their pellets. They used pellet culture system with more complex chondrogenic medium consisted of dexamethasone, ascorbic acid, ITS, TGF- $\beta 3$ and BMP- 6 . Some authors suggest not only the utilization of growth factors but also other physical and mechanical factors, including oxygen tension and hydrostatic pressure (Wagner et al. 2008; Markway et al. 2010; Puetzer et al. 2013).

In summary, MSCs from bone marrow, adipose tissue and umbilical cord shared biological properties such as morphological features, expression of surface antigens, and kinetics of proliferation, but slightly differ in chondrogenic potential. According to these findings we can emphasize that after performing further experiments focused mainly on optimization of culture techniques which may lead into enhancement of chondrogenic differentiation all analyzed MSCs may play important role in cartilage tissue engineering.

Acknowledgements. This work was supported by grants of Ministry of Health of the Slovak Republic No. 2012/4-UKBA-4 and Slovak Research and Development Agency No. 0434-12.

\section{References}

Alimperti S., Lei P., Wen Y., Tian J., Campbell A. M., Andreadis S T. (2014): Serum-free spheroid suspension culture maintains mesenchymal stem cell proliferation and differentiation potential. Biotechnol. Prog. 30, 974-983 http://dx.doi.org/10.1002/btpr.1904

Braun J., Kurtz A., Barutcu N., Bodo J., Thiel A., Dong J. (2013): Concerted regulation of CD34 and CD105 accompanies mesenchymal stromal cell derivation from human adventitial stromal cell. Stem Cells Dev. 22, 815-827 http://dx.doi.org/10.1089/scd.2012.0263

Claus S., Mayer N., Aubert-Foucher E., Chajra H., Perrier-Groult E., Lafont J., Piperno M., Damour O., Mallein-Gerin F. (2012): Cartilage-characteristic matrix reconstruction by sequential addition of soluble factors during expansion of human articular chondrocytes and their cultivation in collagen sponges. Tissue Eng. Part C Methods 18, 104-112

http://dx.doi.org/10.1089/ten.tec.2011.0259

Dominici M., Le Blanc K., Mueller I., Slaper-Cortenbach I., Marini F., Krause D., Deans R., Keating A., Prockop D., Horwitz E. (2006): Minimal criteria for defining multipotent mesenchymal stromal cells. The International Society for Cellular Therapy position statement. Cytotherapy 8, 315-317 http://dx.doi.org/10.1080/14653240600855905

Halasova E., Matakova T., Kavcova E., Musak L., Letkova L., Adamkov M., Ondrusova M., Bukovska E., Singliar A. (2009): Human lung cancer and hexavalent chromium exposure. Neuro Endocrinol. Lett. 30, 182-185

Halasova E., Adamkov M., Matakova T., Vybohova D., Antosova M., Janickova M., Singliar A., Dobrota D., Jakusova V. (2013): Expression of $\mathrm{Ki}-67, \mathrm{Bcl}-2$, survivin and $\mathrm{p} 53$ proteins in patients with pulmonary carcinoma. Adv. Exp. Med. Biol. $756,15-21$ http://dx.doi.org/10.1007/978-94-007-4549-0_3

Heslop J. A., Hammond T. G., Santeramo I., Tort Piella A., Hopp I., Zhou J., Baty R., Graziano E. I., Proto Marco B., Caron A. et al. (2015): Concise review: workshop review: understanding and assessing the risks of stem cell-based therapies. Stem Cells Transl. Med. 4, 389-400

http://dx.doi.org/10.5966/sctm.2014-0110

Hsiao S. T., Asgari A., Lokmic Z., Sinclair R., Dusting G. J., Lim S. Y., Dilley R. J. (2012): Comparative analysis of paracrine factor expression in human adult mesenchymal stem cells derived from bone marrow, adipose, and dermal tissue. Stem Cells Dev. 21, 2189-2203

http://dx.doi.org/10.1089/scd.2011.0674

Kestendjieva S., Kyurkchiev D., Tsvetkova G., Mehandjiev T., Dimitrov A., Nikolov A., Kyurkchiev S. (2008): Characterization of mesenchymal stem cells isolated from the human umbilical cord. Cell Biol. Int. 32, 724-732

http://dx.doi.org/10.1016/j.cellbi.2008.02.002

Lin C. S., Ning H., Lin G., Lue T. F. (2012): Is CD34 truly a negative marker for mesenchymal stromal cells? Cytotherapy 14, $1159-1163$ http://dx.doi.org/10.3109/14653249.2012.729817

Makris E. A., Gomoll A. H., Malizos K. N., Hu J. C., Athanasiou K. A. (2015): Repair and tissue engineering techniques for articular cartilage. Nat. Rev. Rheumatol. 11, 21-34 http://dx.doi.org/10.1038/nrrheum.2014.157

Mardones R., Jofré C. M., Minguell J. J. (2015): Cell therapy and tissue engineering approaches for cartilage repair and/or regeneration. Int. J. Stem Cells 8, 48-53 http://dx.doi.org/10.15283/ijsc.2015.8.1.48

Mara C. S., Duarte A. S., Sartori A., Luzo A. C., Saad S. T., Coimbra I. B. (2010): Regulation of chondrogenesis by transforming growth factor-beta 3 and insulin-like growth factor-1 from 
human mesenchymal umbilical cord blood cells. J. Rheumatol. 37, 1519-1526 http://dx.doi.org/10.3899/jrheum.091169

Markway B. D., Tan G. K., Brooke G., Hudson J. E., Cooper-White J. J., Doran M. R. (2010): Enhanced chondrogenic differentiation of human bone marrow-derived mesenchymal stem cells in low oxygen environment micropellet cultures. Cell Transplant. 19, 29-42 http://dx.doi.org/10.3727/096368909X478560

McNary S. M., Athanasiou K. A., Reddi A. H. (2014): Transforming growth factor $\beta$-induced superficial zone protein accumulation in the surface zone of articular cartilage is dependent on the cytoskeleton. Tissue Eng. Part A, 20, 921-929 http://dx.doi.org/10.1089/ten.tea.2013.0043

Murphy M. K., Huey D. J., Hu J. C., Athanasiou K. A. (2015): TGF$\beta 1$, GDF-5, and BMP-2 stimulation induces chondrogenesis in expanded human articular chondrocytes and marrow-derived stromal cells. Stem Cells 33, 762-773 http://dx.doi.org/10.1002/stem.1890

Pastides P. S., Welck M. J., Khan W. S. (2015): Use of bone marrow derived stem cells in trauma and orthopaedics: A review of current concepts. World J. Orthop. 6, 462-468

Patterson M., Chan D. N., Ha I., Case D., Cui Y., Van Handel B., Mikkola H. K., Lowry W. E. (2012): Defining the nature of human pluripotent stem cell progeny. Cell Res. 22, 178-193 http://dx.doi.org/10.1038/cr.2011.133

Pittenger M. F., Mackay A. M., Beck S. C., Jaiswal R. K., Douglas R., Mosca J. D., Moorman M. A., Simonetti D. W., Craig S., Marshak D. R. (1999): Multilineage potential of adult human mesenchymal stem cells. Science 284, 143-147 http://dx.doi.org/10.1126/science.284.5411.143

Puetzer J., Williams J., Gillies A., Bernacki S., Loboa E. G. (2013): The effects of cyclic hydrostatic pressure on chondrogenesis and viability of human adipose- and bone marrow-derived mesenchymal stem cells in three-dimensional agarose constructs. Tissue Eng. Part A. 19, 299-306 http://dx.doi.org/10.1089/ten.tea.2012.0015

Shademan M., Parham A., Dehghani H. (2015): Enhancment of chondrogenic differentiation potential of equine adipose tissuederived mesenchymal stem cells using TGF- $\beta 3$ and BMP-6. Turk. J. Biol. 39, 1-9

Shang J., Liu H., Li J., Zhou Y. (2014): Roles of hypoxia during the chondrogenic differentiation of mesenchymal stem cells. Curr. Stem Cell Res. Ther. 9, 141-147
http://dx.doi.org/10.2174/1574888X09666131230142459

Shanti R. M., Li W. J., Nesti L. J., Wang X., Tuan R. S. (2007): Adult mesenchymal stem cells: biological properties, characteristics, and applications in maxillofacial surgery. J. Oral Maxillofac. Surg. 65, 1640-1647 http://dx.doi.org/10.1016/j.joms.2007.04.008

Shih D. T., Chen J. C., Chen W. Y., Kuo Y. P., Su C. Y., Burnouf T. (2011): Expansion of adipose tissue mesenchymal stromal progenitors in serum-free medium supplemented with virally inactivated allogeneic human platelet lysate. Transfusion 51, $770-778$ http://dx.doi.org/10.1111/j.1537-2995.2010.02915.x

Subramanian A., Fong C. Y., Biswas A., Bongso A. (2015): Comparative characterization of cells from the various compartments of the human umbilical cord shows that the Wharton's jelly compartment provides the best source of clinically utilizable mesenchymal stem cells. PLoS One 10, e0127992 http://dx.doi.org/10.1371/journal.pone.0127992

Vishwanath V. R., Nadig R. R., Nadig R., Prasanna J. S., Karthik J., Pai V. S. (2013): Differentiation of isolated and characterized human dental pulp stem cells and stem cells from human exfoliated deciduous teeth: An in vitro study. J. Conserv. Dent. 16, 423-428 http://dx.doi.org/10.4103/0972-0707.117509

Wagner D. R., Lindsey D. P., Li K. W., Tummala P., Chandran S. E., Smith R. L., Longaker M. T., Carter D. R., Beaupre G. S. (2008): Hydrostatic pressure enhances chondrogenic differentiation of human bone marrow stromal cells in osteochondrogenic medium. Ann. Biomed. Eng. 36, 813-820 http://dx.doi.org/10.1007/s10439-008-9448-5

Wang Y., Wang F., Zhao H., Zhang X., Chen H., Zhang K. (2014): Human adipose-derived mesenchymal stem cells are resistant to HBV infection during differentiation into hepatocytes in vitro. Int. J. Mol. Sci. 15, 6096-6110 http://dx.doi.org/10.3390/ijms15046096

Zimmerlin L., Donnenberg V. S., Rubin J. P., Donnenberg A. D. (2013): Mesenchymal markers on human adipose stem/progenitor cells. Cytometry A. 83, 134-140 http://dx.doi.org/10.1002/cyto.a.22227

Received: August 17, 2015

Final version accepted: October 27, 2015

First published online: February 18, 2016 